CLINICAL STUDY

\title{
Screening of $L H X 2$ in patients presenting growth retardation with posterior pituitary and ocular abnormalities
}

\author{
Christelle Pérez ${ }^{1}$, Florence Dastot-Le Moal ${ }^{2}$, Nathalie Collot $^{2}$, Marie Legendre ${ }^{1,2}$, Isabelle Abadie ${ }^{3}$, \\ Anne-Marie Bertrand ${ }^{4}$, Serge Amselem ${ }^{1,2}$ and Marie-Laure Sobrier ${ }^{1}$ \\ ${ }^{1}$ Inserm U.933, Hôpital Armand-Trousseau, Université Pierre et Marie Curie-Paris 6, 75571 Paris Cedex 12, France, ${ }^{2}$ Service de Génétique et \\ d'Embryologie Médicales, Assistance Publique-Hôpitaux de Paris, Hôpital Armand Trousseau, 75571 Paris, France, ${ }^{3}$ Service de Pédiatrie, Centre \\ Hospitalier Intercommunal, 94000 Créteil, France and ${ }^{4}$ Service de Pédiatrie 1, Centre Hospitalo-Universitaire, 25000 Besançon, France \\ (Correspondence should be addressed to M-L Sobrier; Email: marie-laure.sobrier@inserm.fr)
}

\begin{abstract}
Background: In humans, pituitary hormone deficiency may be part of a syndrome including extrapituitary defects like ocular abnormalities. Very few genes have been linked to this particular phenotype. In the mouse, Lhx2, which encodes a member of the LIM (Lin-11, Isl-1, and Mec-3) class of homeodomain proteins, was shown to be expressed during early development in the posterior pituitary, eye, and liver, and its expression persists in adulthood in the central nervous system $L h \times 2^{-/-}$mice display absence of posterior pituitary and intermediate lobes, malformation of the anterior lobe, anophthalmia, and they die from anemia.

Methods: We tested the implication of the LHX2 gene in patients presenting pituitary hormone deficiency associated with ectopic or nonvisible posterior pituitary and developmental ocular defects. A cohort of 59 patients, including two familial cases, was studied. Direct sequencing of the LHX2 coding sequence and intron/exon boundaries was performed. LHX2 transcriptional activity on several pituitary promoters (AGSU, PRL, POU1F1, and TSHB) was tested in vitro.

Results: Six heterozygous sequence variations were identified, among which two are novel missense changes (p.Ala203Thr and p.Val333Met). In vitro, LHX2 activates transcription of TSHB, PRL, and POU1F1 promoters in the HEK293 cell line. A synergistic action of POU1F1 and LHX2 was also shown on these promoters. The two missense variations were tested and no significant difference was observed, leading to the conclusion that they are not deleterious.

Conclusions: These results suggest that if LHX2 is involved in pituitary hormone deficiency associated with posterior pituitary and ocular defects, it would be a rare cause of this disease condition.
\end{abstract}

European Journal of Endocrinology 167 85-91

\section{Introduction}

Three lobes of dual embryonic origin compose the pituitary gland. The anterior and intermediate lobes derive from an invagination of the oral ectoderm (Rathke's pouch), whereas the posterior lobe is an evagination of the neuroectoderm from the infundibulum. Rathke's pouch and infundibulum have a close contact during embryonic development and their differentiation depends on the sequential temporal and spatial expression of signaling molecules and transcription factors (1). Among them, three members of the LIM (Lin-11, Isl-1, and Mec-3) homeodomain protein family, LHX2, LHX3, and LHX4, participate in pituitary development $(2,3)$. These transcription factors are made of a homeodomain and two zinc-finger LIM domains, which are involved in protein-protein interactions and may modulate the function of the homeodomain (4). In patients with syndromic forms of combined pituitary hormone deficiency (CPHD), mutations have been identified in LHX3 and LHX4 but not in the LHX2. Other genes (HESX1, SOX2, SOX3, OTX2, and GLI2) have also been implicated in syndromic forms of CPHD (for review, see (5)). In these patients, the molecular analyses are guided by an accurate description of the disease phenotype, which relies on endocrine data, magnetic resonance imaging (MRI) of the pituitary region, and associated extrapituitary abnormalities (6).

Lhx 2 mRNA has been detected in the developing ventral diencephalon in mice (from e9.5) including the infundibulum and the posterior lobe of the pituitary gland (3), and its expression in the central nervous system persists in adulthood (7). The retina also evaginates from the neuroectoderm, and, before birth, Lhx2 is expressed throughout the neural retina, while postnatally, expression becomes restricted to the inner nuclear layer of the retina $(8,9)$. Furthermore, recent studies on mouse models have demonstrated that, during eye development, LHX2 transactivated Six6 in synergy with PAX6 (10). Lhx2 was also shown to be 
important for proper cellular organization and differentiation of the liver (11) in definitive erythropoiesis (8), and it is also an important regulator of hair formation (12) and for complete development of olfactory sensory neurons (13). In mice, functional inactivation of Lhx2 results in a cerebral cortex of reduced size, anophthalmia, as well as absence of posterior pituitary gland and intermediary lobe, and defects in anterior pituitary lobe organization suggesting a mechanism whereby development of the posterior lobe may affect the development of the anterior and intermediate lobes of the pituitary gland. $L h x 2^{-/-}$mice also develop liver fibrosis; erythropoiesis is incomplete resulting in death by severe anemia before birth $(3,8,11)$. Two studies performed in cohorts of patients with ocular abnormalities associated or not with schizencephaly did not permit to involve LHX2 in human pathology $(14,15)$. However, no study has evaluated the implication of LHX2 in pituitary defects.

Herein, the LHX2 gene was analyzed in 59 patients presenting pituitary deficiency associated with ectopic or nonvisible posterior pituitary and ocular abnormalities. Two missense variations were identified and functional tests were performed to assess their potential consequences on the transcription of target genes.

\section{Patients and methods}

\section{Patients}

We studied a cohort of 59 patients, including two familial cases, presenting pituitary deficiency, ectopic, or nonvisible posterior pituitary gland associated with developmental ocular abnormalities. These last anomalies include septo-optic dysplasia (SOD; $n=24$ ), optic nerve hypoplasia $(n=15)$, optic nerve agenesis (ONA; $n=2$ ), coloboma (from retinal to iris; $n=6$ ), optic chiasma abnormalities $(n=2)$, blindness of unknown cause $(n=2)$, and other various ocular signs $(n=8)$. The phenotypic features of all the patients are summarized in Table 1.

Patients provided their written informed consent to perform genetic studies according to the French law.

\section{Mutation analysis}

Genomic DNA was extracted from patients' blood using standard techniques (FlexiGene DNA Kit; Qiagen). The five coding exons of the LHX2 gene were amplified by PCR using primers (available on request) designed from the LHX2 genomic sequence. A robot (MicroLab Star Let, Hamilton robotics, Villebon sur Yvette, France) was used to prepare the PCR mix reaction. After amplification, fragments were purified using Exo-SAPit (GE Healthcare, Cleveland, OH, USA) and both forward and reverse strands were sequenced using Big Dye DNA sequencing kit (Big Dye Terminator v3.1 Cycle Sequencing Kit; Applied Biosystems, Foster City, CA, USA) with primers available on request. Reactions were run on the 3730XL sequencer (Applied Biosystems) and analyzed with SeqScape v2.6 Software (Applied Biosystems). Sequence variations were numbered with the adenine of the ATG initiation codon as the first nucleotide (NC_000009.11).

Table 1 Main phenotypic features of the 59 patients.

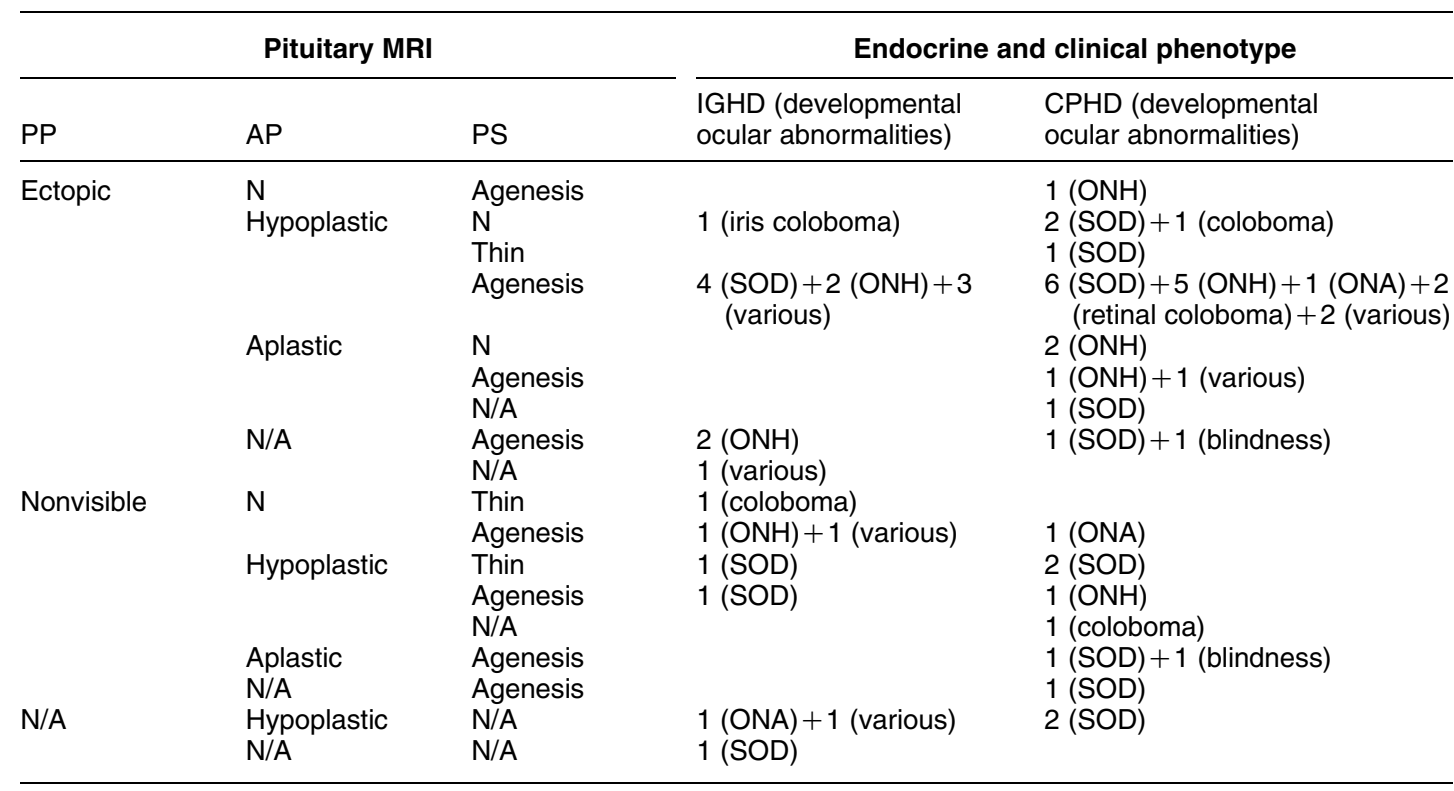

PP, posterior pituitary; AP, anterior pituitary; PS, pituitary stalk; $\mathrm{N}$, normal; ONH, optic nerve hypoplasia; ONA, optic nerve agenesis; SOD, septo-optic dysplasia; vis, visible; N/A, not available; various: cataract, optic nerve misorientation, optic neuritis, microphthalmia, ocular asymmetry, exophthalmia, wards excavated. 


\section{Plasmid constructs}

The wild-type LHX2 cDNA was amplified from human pituitary cDNA (Human Pituitary Gland QUICK-Clone cDNA; Clontech) using primers LHX2 cDNA - F: 5'-CCGCCGCGATGCTGTTCCACAGTC-3' and LHX2 cDNA - R: 5'-GAGTCATTAGAAAAGGTTGGTAAGAGTC-3'. The human LHX2-wt cDNA was subcloned into the expression vector pcDNA3 (pcDNA3.1/V5-His TOPO TA Expression Kit; Invitrogen) and then named p.LHX2-wt. The Val333Met and Ala203Thr variants were introduced in p.LHX2-wt using the Quick Change Site Directed Mutagenesis Kit (Stratagene, La Jolla, CA, USA); the resulting constructs, which were confirmed by sequencing, were designated p.LHX2-V333M and p.LHX2-A203T respectively.

The human POU1F1 cDNA (p.POU1F1-wt) (16) was previously cloned into the pTracer expression vector (Invitrogen). The human thyrotropin $\beta$ subunit (TSHB) promoter (17), the human prolactin $(P R L)$ promoter (16), the human POU1F1 promoter (18), and a $547 \mathrm{bp}$ fragment (nt -548 to $\mathrm{nt}-1$ ) of the human $\alpha$-GSU (AGSU) promoter were cloned into the pGL3 basic luciferase reporter vector (Promega) according to the standard procedures.

\section{Cell culture and transfections}

HEK293, GH4C1, and GH3 cells were grown in DMEM medium (Invitrogen) containing 10\% (v/v) FCS at $37{ }^{\circ} \mathrm{C}$. All transfections were performed at $60 \%$ confluence in 12-well culture plates by the Lipofectamine-Plus method (Invitrogen) in OptiMEM according to the manufacturer's standard protocol. Cells were cotransfected with $50 \mathrm{ng}$ reporter constructs and 25 or $50 \mathrm{ng}$ empty pcDNA3 vector and/or p.LHX2-wt, p.LHX2-V333M, and p.LHX2-A203T in the presence or absence of the p.POU1F1-wt construct.

\section{Luciferase activity assays}

Forty-eight hours after transfection, cell extracts were prepared and assayed for luciferase activity using the Promega assay system. Luciferase activity was normalized to protein concentration, which was

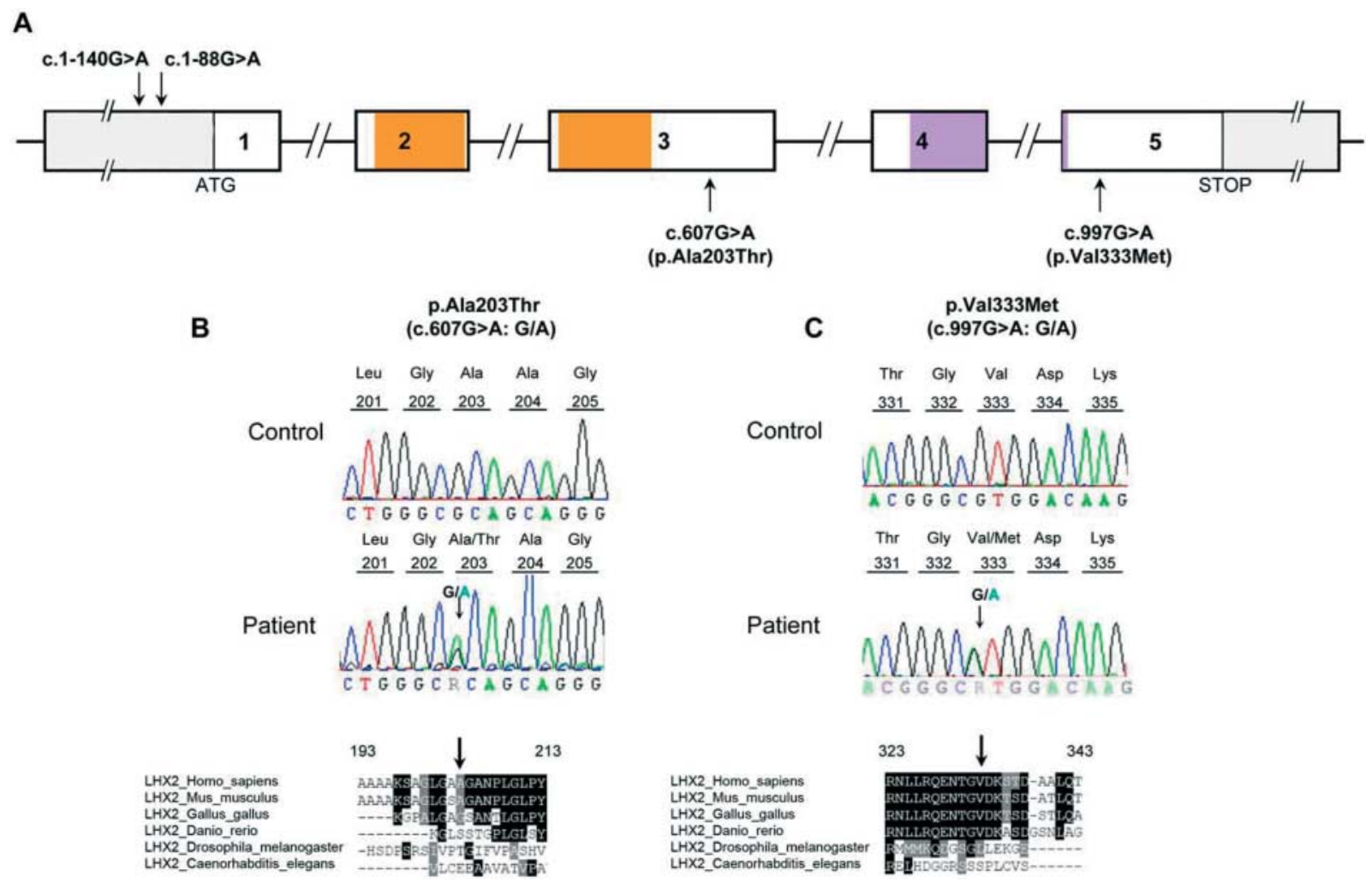

Figure 1 Human LHX2 genomic organization and new heterozygous variations identified in the cohort. (A) Schematic representation of human $L H X 2$ genomic organization. The five coding exons (1-5) are represented by light gray or white/colour boxes, depicting untranslated o or translated sequences, respectively. The LIM domains (LIM1 and LIM2) and homeodomain (HD) are shown in orange and purple respectively. The locations of the translation initiation codon (ATG) and stop codon are indicated. The exons are drawn to scale except exons 1 and 5 . Newly identified changes are indicated by arrows. (B and C) Electrophoreograms for a control and the patient (top) and conservation of amino acids 203 and 333 of the LHX2 protein (bottom) are shown. The LHX2 amino acid sequence was aligned using BOXSHADE 3.21 Software with those of several species. 
measured using the Coomassie Plus protein assay reagent kit (Pierce, Rockford, IL, USA). Each transfection experiment (in triplicate) was performed independently at least three times.

\section{Results}

\section{Cohort selection}

Based on the Lhx2 expression studies performed in the mouse and the phenotypic features of $\operatorname{Lh} x 2^{-1-}$ mice, the LHX2 gene was screened for mutations in a cohort of patients with pituitary hormone deficiency associated with ectopic or nonvisible posterior pituitary gland and ocular abnormalities (see Patients and methods). Twenty-one patients displayed isolated $\mathrm{GH}$ deficiency (IGHD) and thirty-eight had CPHD; a majority $(37 / 59)$ displayed anterior pituitary hypoplasia, ectopic posterior pituitary, and a pituitary stalk that was not visible (Table 1). Before LHX2 gene sequencing, these patients were analyzed for one or several genes (depending on their pituitary phenotype, the MRI aspect, their gender and the associated abnormalities) known to be involved in pituitary hormone deficiency associated with ocular and/or posterior pituitary abnormalities: HESX1 in 93\% of the patients (phenotype similar to that expected for LHX2), OTX2 in 10\% (patients with a coloboma), SOX2 in 38\% (patients with gonadotrope deficiency), and SOX3 in 45\% (male patients).

\section{Identification of new LHX2 sequence variations}

Six heterozygous variations were identified (Table 2). The c.726-21G $>$ T and c.1017G $>$ C (p.Ala339Ala) variations were previously described in patients with schizencephaly (five and one patients respectively) (15). DNAs of two patients from the same family were analyzed in the current study: the girl presented two heterozygous polymorphisms, c.783> G/C (p.Pro261Pro) and c.934-51G>A, whereas her affected brother was homozygous at these positions. This result allowed us to exclude LHX2 as the causative gene in this family under the assumption of a recessive transmission. Four new base changes have been identified in this study: two of them, c. $1-88 \mathrm{G}>\mathrm{A}$ and

Table 2 Patients' phenotypes in whom sequence changes were identified in the $L H X 2$ gene.

\begin{tabular}{|c|c|c|c|c|c|c|c|}
\hline \multirow[b]{2}{*}{ Patients } & \multirow[b]{2}{*}{$\begin{array}{l}\text { Age at } \\
\text { diagnosis }\end{array}$} & \multicolumn{3}{|c|}{ Phenotype } & \multirow[b]{2}{*}{$\begin{array}{l}\text { Nucleotide } \\
\text { variation }\end{array}$} & \multirow[b]{2}{*}{$\begin{array}{l}\text { Amino acid } \\
\text { change }\end{array}$} & \multirow[b]{2}{*}{ SNP id } \\
\hline & & $\begin{array}{l}\text { Pituitary hormone } \\
\text { deficiency }\end{array}$ & $\begin{array}{l}\text { Pituitary } \\
\text { morphology }\end{array}$ & $\begin{array}{l}\text { Ocular and other } \\
\text { abnormalities }\end{array}$ & & & \\
\hline \multirow[t]{2}{*}{ Case 1} & Adult & IGHD & HAP & Congenital cataract & $\begin{array}{r}\text { c. } 1-140 \mathrm{G} \\
>\mathrm{A}: \mathrm{G} / \mathrm{A}\end{array}$ & - & New \\
\hline & & & $\begin{array}{l}\text { Not vis. PP } \\
\text { PS N/A }\end{array}$ & Incisor malposition & & & \\
\hline \multirow[t]{2}{*}{ Case 2} & Adult & IGHD & HAP & Optic neuritis & $\begin{array}{l}\text { c. } 1-88 \mathrm{G} \\
\quad>\mathrm{A}: \mathrm{G} / \mathrm{A}\end{array}$ & - & New \\
\hline & & & $\begin{array}{l}\text { EPP } \\
\text { Not vis. PS }\end{array}$ & Arnold-Chiari & & & \\
\hline \multirow[t]{3}{*}{ Case 3} & 2 years & IGHD & HAP & $\begin{array}{l}\text { SOD, glaucoma, } \\
\text { strabismus }\end{array}$ & $\begin{array}{l}\text { c.607G } \\
\quad>A: G / A\end{array}$ & p.Ala203Thr & New \\
\hline & & & Not vis. PP & Holoprosencephaly & & & \\
\hline & & & PS N/A & $\begin{array}{l}\text { Diabetes } \\
\text { CC abnormality }\end{array}$ & & & \\
\hline \multirow[t]{3}{*}{ Case 4} & 1 month & CPHD (GH, PRL, & AAP & SOD & c. $726-21 G$ & - & rs149426877 \\
\hline & & $\begin{array}{l}\text { TSH, and } \\
\text { cortisol) }\end{array}$ & EPP & Cleft palate & $>\mathrm{T}: \mathrm{G} / \mathrm{T}$ & & $\begin{array}{l}\text { Five patients with } \\
\text { schizencephaly } \\
\text { Mellado et al. (15) }\end{array}$ \\
\hline & & & PS N/A & CC abnormality & & & \\
\hline \multirow[t]{3}{*}{ Case 5} & 7 years & IGHD & HAP & SOD & c.997G & p.Val333Met & rs151109428 \\
\hline & & & EPP & $\begin{array}{l}\text { Septum pellucidum } \\
\text { agenesis }\end{array}$ & $>A: G / A$ & & $1 / 10000$ frequency \\
\hline & & & Not vis. PS & & & & \\
\hline \multirow[t]{3}{*}{ Case 6} & 3 years & IGHD & HAP & SOD, coloboma, and & c. $1017 \mathrm{G}$ & p.Ala339Ala & rs138022431 \\
\hline & & & EPP & microphthalmia & $>\mathrm{C}: \mathrm{G} / \mathrm{C}$ & & $\begin{array}{l}\text { One patient with } \\
\text { schizencephaly } \\
\text { Mellado et al. (15) }\end{array}$ \\
\hline & & & Not vis. PS & & & & \\
\hline
\end{tabular}

HAP, hypoplastic anterior pituitary; AAP, aplastic anterior pituitary; EPP, ectopic posterior pituitary; PP, posterior pituitary; PS, pituitary stalk; SOD, septo-optic dysplasia; CC, corpus callosum; N/A, not available; vis., visible. The new variations are shown in boldface. 
c. $1-140 \mathrm{G}>\mathrm{A}$, are located in the $5^{\prime}$ transcribed UTR

(Fig. 1A) and the two others are missense variations.

The first heterozygous missense variant consists of a G-to-A transition at position 607 (c.607G > A) in exon 3, changing alanine 203 to threonine (p.Ala203Thr; Fig. $1 \mathrm{~A}$ and $\mathrm{B}$ ), which is located between the LIM2 domain and the homeodomain. This variation was identified in an adopted patient presenting IGHD, nonvisible posterior pituitary gland, SOD, and glaucoma. This amino acid is not conserved (Fig. 1B, bottom). Considering that the child is adopted, parent's DNA analysis will not be informative; however, as this variation involves a $\mathrm{CpG}$ dimer, a de novo mutation cannot be excluded.

The second heterozygous variant, c.997G $>$ A (p.Val333Met; exon 5), was identified in a patient with IGHD, a hypoplastic anterior pituitary, ectopic posterior pituitary, and SOD (Fig. 1A and C). The healthy mother is heterozygous for the variation. Valine 333 does not belong to a known functional domain but is well conserved among species, and methionine is never found at this position (Fig. 1C, bottom).

\section{LHX2 activates the TSHB subunit, PRL, and POU1F1 promoters in HEK293 cell line}

Previous studies have shown that LHX2 activates the rat Tshb promoter in GH3 and ATSH cells (19) and the mouse AGsu promoter in HEK293 cell lines (20).
The consensus target sequences (G/T CAAT T/A (19) or TAAT T/A G $(13,21)$ ) were also found in the PRL and POU1F1 promoters (data not shown). We therefore tested the ability of LHX2 to activate these promoters (i.e. TSHB, PRL, AGSU, and POU1F1) with the aim to assess the functional consequences of the Ala203Thr and Val333Met variations.

To identify the cell line in which these experiments should be done, GH3, GH4C1 (rat pituitary cell lines), and HEK293 (human embryonic kidney) cells were transfected with the expression plasmid p.LHX2-wt and with TSHB, PRL, POU1F1, or AGSU promoter constructs. As shown in Fig. 2, compared with the empty vector, LHX2 activates the TSHB promoter in these three cell lines (Fig. 2A, B and C). However, the activation of the other promoters was observed only in HEK293 (Fig. 2C), and AGSU promoter activation was never detected. The HEK293 cell line will therefore be used in the following tests.

\section{LHX2 variations are probably not implicated in the disease phenotype}

Even if alanine 203 and valine 333 of LHX2 are not located in identified functional domains, and despite the fact that the Polyphen and SIFT programs are not in favor of disease-causing mutations, they may be important for efficient transcriptional activity. Thus, luciferase assays were performed in HEK293 to test the
A

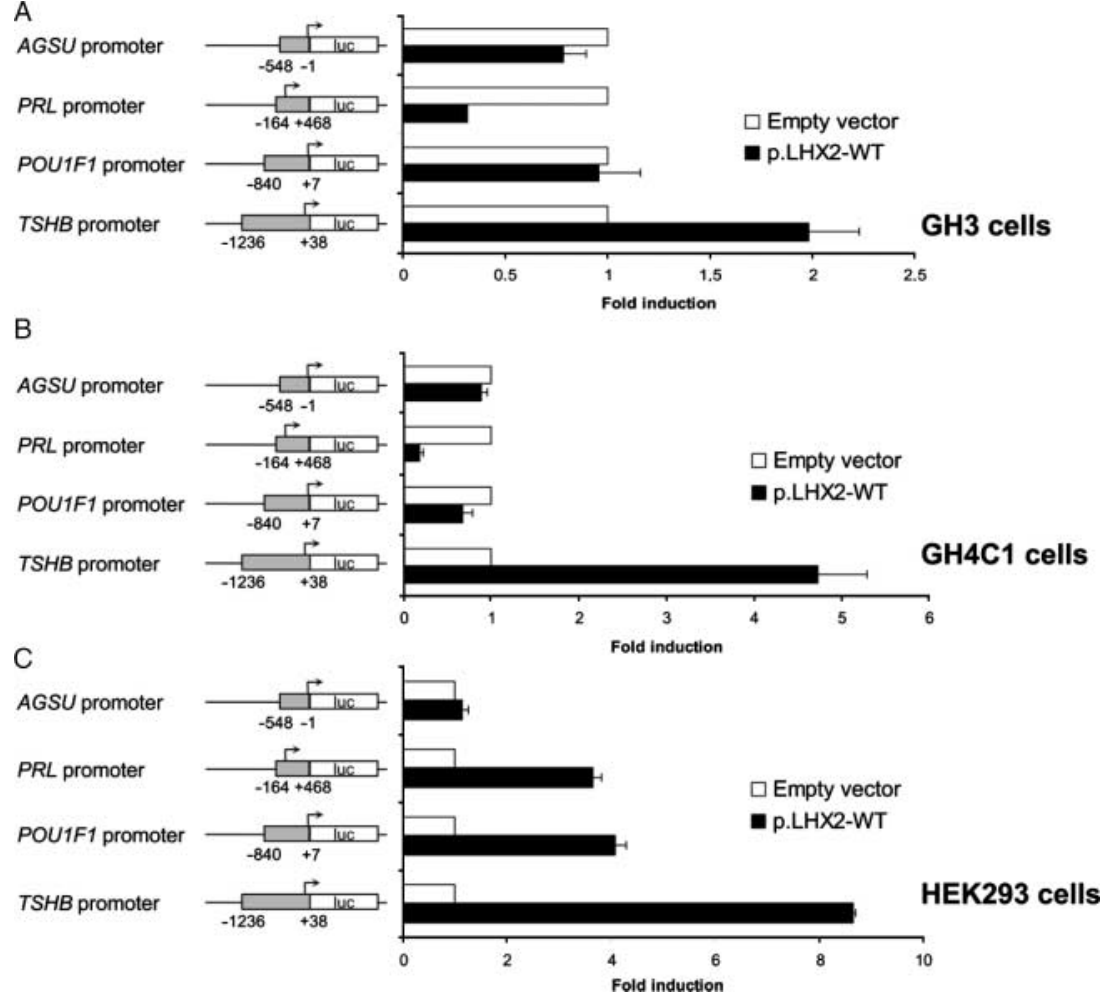

Figure 2 LHX2 transcription activation on the AGSU, TSHB, POU1F1, and PRL promoters in three cell lines. GH3 (A), GH4C1 (B), and HEK293 (C) cells are cotransfected with $50 \mathrm{ng}$ promoters fused to luciferase reporter gene and $50 \mathrm{ng}$ p. LHX2-wt. Each transfection was performed in triplicate and results are expressed as fold induction relative to control empty vector. 
transcriptional activity of LHX2-V333M and LHX2A203T. As shown in Fig. 3A, LHX2-wt is able to activate by sevenfold the human TSHB promoter compared with cells transfected with an empty vector. The transcriptional activity of the LHX2-V333M and LHX2-A203T proteins tested on the same promoter was found to be similar to the wild-type protein (about eight and sixfold respectively). This experiment was also performed on the PRL and the POU1F1 promoters: although LHX2-wt activates these promoters (three and sevenfold respectively), no significant difference was observed with the two LHX2 variants (Fig. 3B and C).

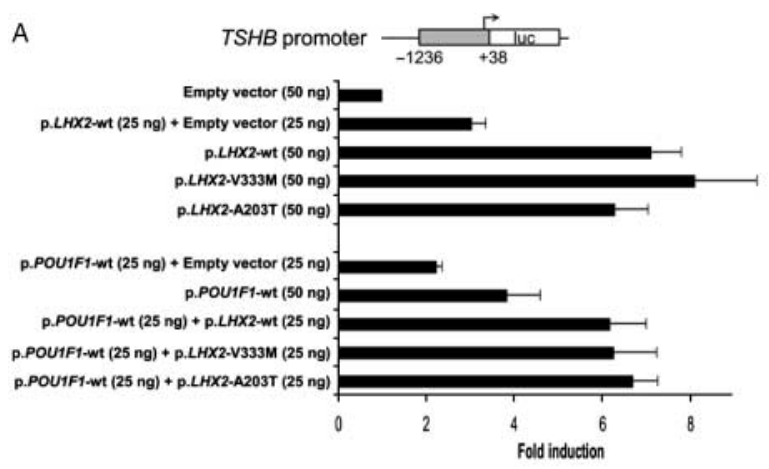

B
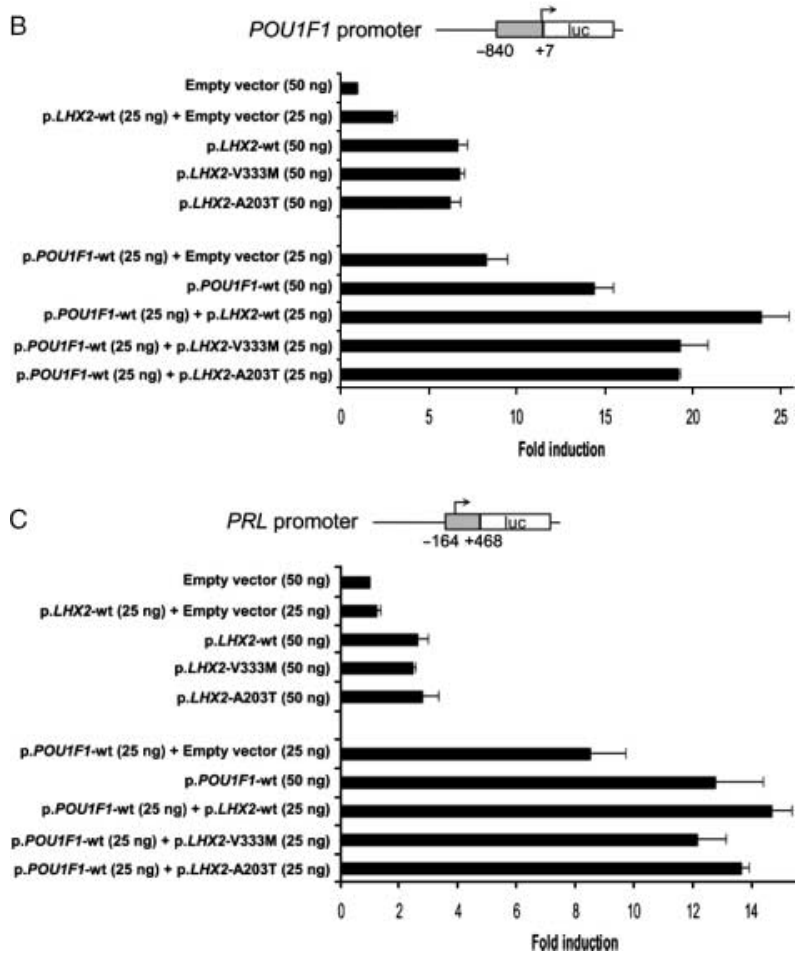

Figure 3 Consequences of the $L H X 2$ variations on transcriptional activity and LHX2/POU1F1 coactivation on the TSHB, POU1F1, and $P R L$ promoters. HEK293 cells were transfected with $50 \mathrm{ng}$ TSHB (A), POU1F1 (B), and PRL (C) promoter constructs in the presence of pcDNA3 empty vector, or p.LHX2-wt, p.LHX2-V333M, p.LHX2-A203T, and p.POU1F1-wt. A representative experiment (performed in triplicate) from three independent experiments is presented.
In order to test a synergistic action of POU1F1 and LHX2 (as it is the case for POU1F1 and LHX3 (22)), HEK293 cells were cotransfected with the p.POU1F1-wt and the p.LHX2 constructs (wild-type, V333M or A203T). Coexpression of the POU1F1-wt and LHX2-wt proteins resulted in an increased transcriptional activity on all promoters tested compared with activation in the presence of p.LHX2-wt or p.POU1F1-wt alone, demonstrating a synergistic effect of POU1F1 and LHX2 (Fig. 3A, B and C). The same results were obtained with p.LHX2-V333M and p.LHX2-A203T. These observations suggest that the two identified LHX2 missense variations are not deleterious.

\section{Discussion}

LHX2 plays a critical role in the development of several organs including the pituitary gland and eye. DNA samples from a selected cohort of patients presenting pituitary deficiency with posterior pituitary and developmental ocular abnormalities were sequenced for mutations in the LHX2 gene. Among the six heterozygous variations detected, four are novel and two of them lead to amino acid change, the p.Ala203Thr and the p.Val333Met missense variations. This prompted us to test the capacity of LHX2 to activate transcription from several candidate promoter targets.

Binding sequences for LHX2 determined by Kim (19), Hirota (13), and Roberson (21) are present in the AGSU, TSHB, PRL, and POU1F1 promoters. Showalter et al. (20) showed activation of the mouse AGsu promoter by mouse LHX2 but not by axolotl LHX2; in the current study, human LHX2 does not activate this promoter. These data may reflect species-specific effects. Moreover, the LHX2-wt protein negatively regulates the PRL promoter in pituitary cell lines by a so far unknown mechanism. Activation of the rat Tshb promoter by LHX2 has been demonstrated in thyrotrope cell lines (19) and, here, in all cell lines tested. In transfected HEK293 cells, LHX2 is able to activate the human TSHB, PRL, and POU1F1 promoters. No significant differences were detected with the mutant proteins (LHX2-A203T and LHX2-V333M) compared with the wild-type LHX2 protein.

To determine whether POU1F1 could be a coactivator of LHX2, as it was shown for LHX3 (22), similar experiments were performed in cells coexpressing LHX2 and POU1F1. While no synergy was detected between LHX2 and POU1F1 on the rat Tshb promoter (19), a synergy was observed in this study, not only for the human TSHB promoter but also for all tested promoters. There was no difference between the LHX2 variants and the wild-type protein suggesting again that LHX2V333M and LHX2-A203T could be uncommon polymorphisms. 
The current study represents the third screening of LHX2 for mutations $(14,15)$. The data obtained so far do not implicate this gene in human pathology. If they exist, LHX2 mutations would therefore represent a rare cause of pituitary deficiency with developmental ocular abnormalities. These data raise the question of the possible importance of other phenotypic criteria, such as anemia, for the identification of patients in whom LHX2 could be analyzed.

\section{Declaration of interest}

The authors declare that there is no conflict of interest that could be perceived as prejudicing the impartiality of the research reported.

\section{Funding}

This work was supported by the Agence Nationale de la Recherche (ANR-08-GENO-026-02). C Pérez is a recipient of a fellowship from the Université Pierre et Marie Curie (Paris, France).

\section{Acknowledgements}

The authors are grateful to the patients for agreeing to participate in the study. They also thank Camille Barbier for technical assistance.

\section{References}

1 Zhu X, Gleiberman AS \& Rosenfeld MG. Molecular physiology of pituitary development: signaling and transcriptional networks. Physiological Reviews 200787 933-963. (doi:10.1152/physrev. 00006.2006)

2 Sheng HZ, Moriyama K, Yamashita T, Li H, Potter SS, Mahon KA \& Westphal H. Multistep control of pituitary organogenesis. Science 1997278 1809-1812. (doi:10.1126/science.278.5344. 1809)

3 Zhao Y, Mailloux CM, Hermesz E, Palkovits M \& Westphal H. A role of the LIM-homeobox gene Lhx2 in the regulation of pituitary development. Developmental Biology 2010337 313-323. (doi:10.1016/j.ydbio.2009.11.002)

4 Dawid IB, Breen JJ \& Toyama R. LIM domains: multiple roles as adapters and functional modifiers in protein interactions. Trends in Genetics 199814 156-162. (doi:10.1016/S0168-9525(98) 01424-3)

5 Wit JM, Kiess W \& Mullis P. Genetic evaluation of short stature. Best Practice \& Research. Clinical Endocrinology \& Metabolism 2011 25 1-17. (doi:10.1016/j.beem.2010.06.007)

6 Di Iorgi N, Allegri AE, Napoli F, Bertelli E, Olivieri I, Rossi A \& Maghnie M. The use of neuroimaging for assessing disorders of pituitary development. Clinical Endocrinology 201276 161-176. (doi:10.1111/j.1365-2265.2011.04238.x)

$7 \mathrm{Xu}$ Y, Baldassare M, Fisher P, Rathbun G, Oltz EM, Yancopoulos GD, Jessell TM \& Alt FW. LH-2: a LIM/homeodomain gene expressed in developing lymphocytes and neural cells. PNAS 199390 227-231. (doi:10.1073/pnas.90.1.227)

8 Porter FD, Drago J, Xu Y, Cheema SS, Wassif C, Huang SP, Lee E, Grinberg A, Massalas JS, Bodine D, Alt F \& Westphal H. Lhx2, a LIM homeobox gene, is required for eye, forebrain, and definitive erythrocyte development. Development 1997124 2935-2944.
9 Yun S, Saijoh Y, Hirokawa KE, Kopinke D, Murtaugh LC, Monuki ES \& Levine EM. Lhx2 links the intrinsic and extrinsic factors that control optic cup formation. Development 2009136 3895-3906. (doi:10.1242/dev.041202)

10 Tetreault N, Champagne MP \& Bernier G. The LIM homeobox transcription factor Lhx 2 is required to specify the retina field and synergistically cooperates with Pax6 for Six6 trans-activation. Developmental Biology 2009327 541-550. (doi:10.1016/j.ydbio. 2008.12.022)

11 Wandzioch E, Kolterud A, Jacobsson M, Friedman SL \& Carlsson L. Lhx $2^{-1-}$ mice develop liver fibrosis. PNAS 2004 101 16549-16554. (doi:10.1073/pnas.0404678101)

12 Tornqvist G, Sandberg A, Hagglund AC \& Carlsson L. Cyclic expression of $\mathrm{lhx} 2$ regulates hair formation. PLoS Genetics 20106 e1000904. (doi:10.1371/journal.pgen.1000904)

13 Hirota J \& Mombaerts P. The LIM-homeodomain protein Lhx2 is required for complete development of mouse olfactory sensory neurons. PNAS 2004101 8751-8755. (doi:10.1073/pnas. 0400940101)

14 Desmaison A, Vigouroux A, Rieubland C, Peres C, Calvas P \& Chassaing N. Mutations in the LHX2 gene are not a frequent cause of micro/anophthalmia. Molecular Vision 201016 2847-2849.

15 Mellado C, Poduri A, Gleason D, Elhosary PC, Barry BJ, Partlow JN, Chang BS, Shaw GM, Barkovich AJ \& Walsh CA. Candidate gene sequencing of LHX2, HESX1, and SOX2 in a large schizencephaly cohort. American Journal of Medical Genetics. Part A 2010 152A 2736-2742. (doi:10.1002/ajmg.a.33684)

16 Tenenbaum-Rakover Y, Sobrier ML \& Amselem S. A novel POU1F1 mutation (p.Thr168IlefsX7) associated with an early and severe form of combined pituitary hormone deficiency: functional analysis and follow-up from infancy to adulthood. Clinical Endocrinology 201175 214-219. (doi:10.1111/j.1365-2265. 2011.04028.x)

17 Sobrier ML, Attie-Bitach T, Netchine I, Encha-Razavi F, Vekemans M \& Amselem S. Pathophysiology of syndromic combined pituitary hormone deficiency due to a LHX3 defect in light of LHX3 and LHX4 expression during early human development. Gene Expression Patterns 20045 279-284. (doi:10. 1016/j.modgep.2004.07.003)

18 Machinis K \& Amselem S. Functional relationship between LHX4 and POU1F1 in light of the LHX4 mutation identified in patients with pituitary defects. Journal of Clinical Endocrinology and Metabolism 200590 5456-5462. (doi:10.1210/jc.2004-2332)

19 Kim KK, Song SB, Kang KI, Rhee M \& Kim KE. Activation of the thyroid-stimulating hormone beta-subunit gene by LIM homeodomain transcription factor Lhx2. Endocrinology 2007 148 3468-3476. (doi:10.1210/en.2006-1088)

20 Showalter AD, Yaden BC, Chernoff EA \& Rhodes SJ. Cloning and analysis of axolotl ISL2 and LHX2 LIM-homeodomain transcription factors. Genesis 200438 110-121. (doi:10.1002/gene. 20007)

21 Roberson MS, Schoderbek WE, Tremml G \& Maurer RA. Activation of the glycoprotein hormone alpha-subunit promoter by a LIM-homeodomain transcription factor. Molecular and Cellular Biology 199414 2985-2993. (doi:10.1128/MCB. 140502985)

22 Bach I, Rhodes SJ, Pearse RV II, Heinzel T, Gloss B, Scully KM, Sawchenko PE \& Rosenfeld MG. P-Lim, a LIM homeodomain factor, is expressed during pituitary organ and cell commitment and synergizes with Pit-1. PNAS 199592 2720-2724. (doi:10. 1073/pnas.92.7.2720)

Received 11 January 2012

Revised version received 13 April 2012

Accepted 24 April 2012 